Cite this: Polym. Chem., 2014, 5, 882

\title{
Poly(ionic liquid)s-based nanocomposite polyelectrolytes with tunable ionic conductivity prepared via SI-ATRP $\dagger$
}

\author{
Ping Wang, ${ }^{a}$ Yin-Ning Zhou, ${ }^{b}$ Jiang-Shui Luoc and Zheng-Hong Luo*b
}

In this study, a novel kind of organic-inorganic core-shell $\mathrm{SiO}_{2}$-poly(p-vinylbenzyl) trimethylammonium tetrafluoroborate $\left(\mathrm{SiO}_{2}-\mathrm{P}[\mathrm{VBTMA}]\left[\mathrm{BF}_{4}\right]\right)$ nanoparticle was well designed and successfully synthesized via surface-initiated atom transfer radical polymerization (SI-ATRP). Fourier transform infrared spectroscopy (FT-IR), ${ }^{1} \mathrm{H}$ nuclear magnetic resonance $\left({ }^{1} \mathrm{H}\right.$ NMR), X-ray photoelectron spectroscopy (XPS), dynamic light scattering (DLS) and scanning electron microscopy (SEM) were used to confirm the formation of the core-shell nanoparticles and the surface modification. In order to overcome the challenge of the characterization of the number average molecular weight of poly(ionic liquid)s, "sacrificial initiator" method was used here employing a trimethylsilyl (TMS)-labeled initiator as the NMR marker for integration. In addition, good thermal stability of the new hybrid polyelectrolyte was proved by thermogravimetric analysis. The electrochemical impedance measurements revealed that the room temperature conductivity reached $10^{-4} \mathrm{~S} \mathrm{~cm}^{-1}$, which is much higher than that of the pure poly(ionic liquid)s and varies with the amount of the grafted polymer and the test temperature. The X-ray diffraction (XRD) tests further investigated the crystal structure of the nanocomposite and pure P[VBTMA][BF 4 . The

Received 30th July 2013

Accepted 17th September 2013

DOI: 10.1039/c3py01025b

www.rsc.org/polymers temperature dependence of ionic conductivity conforms to Arrhenius behavior for both of the nanocomposites and the pure polymer. The results indicated that the SI-ATRP approach provided a simple and versatile route to tune the ionic conductivity of the hybrid nanoparticles by changing the chain length of the grafted polymer, which can be potentially used in a variety of electrochemical devices.

\section{Introduction}

Ion-conducting materials are important components in a variety of energy conversion devices, such as all-solid-state lithiummetal-polymer batteries, fuel cells, dye-sensitized solar cells, light-emitting electrochemical cells, and other electrochemical devices. ${ }^{1,2}$ Poly(ionic liquid)s as one type of polymer electrolyte, which improve the stability of ionic liquids by tethering ion conducting groups to the polymer backbone, were found to play an enabling role in some fields of polymer chemistry and materials science. ${ }^{3-6}$ Studies of poly(ionic liquid)s have been overwhelmingly concentrated on the introduction of polymerizable groups to the ionic liquid cations, where the common groups are acryloyl or vinyl. However, the polymerization of ionic compounds inevitably reduces the ion motion and thus the

${ }^{a}$ Department of Chemical and Biochemical Engineering, College of Chemistry and Chemical Engineering, Xiamen University, Xiamen 361005, P. R. China

${ }^{b}$ Department of Chemical Engineering, School of Chemistry and Chemical Engineering, Shanghai Jiao Tong University, Shanghai 200240, P. R. China. E-mail: luozh@sjtu. edu.cn; Fax: +86-21-54745602; Tel: +86-21-54745602

'Department of Metallurgy and Materials Engineering, KU Leuven, Kasteelpark Arenberg 44 - box 2450, 3001 Leuven, Belgium

$\dagger$ Electronic supplementary information (ESI) available. See DOI: 10.1039/c3py01025b resulting ionic conductivity at ambient temperature is relatively too low for commercial applications. Much work has been carried out to optimize the polymer electrolytes to enhance their ionic conductivity, thermal stability, and electrochemical stability as the prerequisite for their use in lithium rechargeable batteries at ambient temperature. ${ }^{7-10}$ For example, the formation of welldefined polymer/inorganic nanoparticle hybrid materials are critical to the development of nanomaterials with desired optical, electric, magnetic, mechanical, and electrochemical properties. ${ }^{11-18}$ Various nanoscale cores, including montmorillonite, gold, CdSe, aluminum oxide and silica, have been reported. ${ }^{\mathbf{1 4 - 1 6 , 1 9}}$ Nanosilica, one of the most common spherical nanoscale particles, is chemically inert but allows irreversible surface modification by reaction of the surface silanol groups. ${ }^{19,20}$ Due to the nanoscale effects, polymer/silica nanocomposites can often exhibit dramatic improvements in strength, modulus, heat resistance, gas permeability barrier properties and so on. ${ }^{\mathbf{2 1 , 2 2}}$ What is more, the addition of the non-conducting filler produces an increase in the conductivity of both semi-crystalline and amorphous polymer electrolytes. ${ }^{23-27}$ Therefore, by incorporating poly(ionic liquid)s onto inorganic nanoparticles to form coreshell structures, it is possible to provide complementary functionality (i.e., structural stability) and transport tunability to ionconducting materials. 
Hybrid nanoparticles can be prepared by either physical adsorption or covalent grafting techniques including "grafting to" and "grafting from" methods. Because of its high tethering density, the "grafting from" method is more attractive. Controlled/"living" radical polymerizations, such as atom transfer radical polymerization (ATRP), have been shown to give very satisfactory results because of their high tethering density by the "grafting from" method. ${ }^{28-31}$ It has been widely studied for planar surfaces, ${ }^{32-40}$ and some work on spherical particles has also been reported. ${ }^{41-45}$ Surface initiated-ATRP (SI-ATRP) on nanosilica particles was first reported by Patten et al., who discovered that it provides a good strategy for formation of core-shell microspheres with a controllable shell layer. ${ }^{46}$

As a kind of hydrophilic ionic liquid monomer, ( $p$-vinylbenzyl) trimethylammonium tetrafluoroborate ([VBTMA] $\left[\mathrm{BF}_{4}\right]$ ) was chosen due to its ion-conducting system for applications that involve exposure to air and inevitable contact with water vapor. The presence of water is anticipated to have a strong effect on transport properties of the nanocomposites as it can be absorbed by the hydrophilic poly( $p$-vinylbenzyl) trimethylammonium tetrafluoroborate (P[VBTMA $\left.]\left[\mathrm{BF}_{4}\right]\right)$ shell, and thus increases the volume fraction of the conducting phase allowing for greater mobility of $\mathrm{P}[\mathrm{VBTMA}]\left[\mathrm{BF}_{4}\right]$ polymer chains, resulting in enhanced ionic conductivity. ${ }^{22,27}$

Therefore, we try to synthesize a novel kind of organic-inorganic nanoparticle with a core-shell structure which combines the strength properties and the ion-conducting properties with a synergistic effect. Firstly, [VBTMA $]\left[\mathrm{BF}_{4}\right]$ monomers were grafted onto the nanosilica particles, which have a small size, high specific surface area and provided as a rigid support, by SI-ATRP. The trimethylsilyl (TMS)-labeled "sacrificial initiator" method $^{33,47-50}$ was applied to trace the polymerization and characterize the molecular weight of poly(ionic liquid)s. In addition, the ionic conductivity and ion conduction mechanism of the nanocomposites were investigated initially. Such an insight into the fundamental structure-property relationship which governs ion conduction is critical for developing next generation of ionconducting materials.

\section{Experimental}

\subsection{Materials}

Nanosilica (with an average particle size of $14 \mathrm{~nm}$ and a specific surface area of $\left.200 \pm 25 \mathrm{~m}^{2} \mathrm{~g}^{-1}\right)$, ( $p$-vinylbenzyl)trimethylammonium chloride ([VBTMA][Cl], 99\%), deuterated chloroform $\left(\mathrm{CDCl}_{3}, 99.9 \%\right)$, deuterated dimethylsulfoxide- $d_{6}$ (DMSO$\left.d_{6}, \quad 99.9 \%\right)$, and 1,1,4,7,7-pentamethyldiethylenetriamine (PMDETA, 98\%) were purchased from Sigma Aldrich. Nanosilica was preheated at $110{ }^{\circ} \mathrm{C}$ under vacuum overnight. 3-Aminopropyltriethoxysilane (APTES, 98\%) was bought from Alfa Aesar. 2-Bromoisobutyryl bromide (BiBB, 98\%) was obtained from A Better Choice for Research Chemicals $\mathrm{GmbH}$ \& Co. KG (ABCR). Sodium tetrafluoroborate $\left(\mathrm{NaBF}_{4}, 99 \%\right)$ and 2-(trimethylsilyl)ethanol (99\%) were purchased from Aladdin. CuCl (99\%, Sinopharm Chemical Reagent Co., Ltd (SCRC)) was purified by washing it with acetic acid and methanol alternatively three times and then dried under vacuum at $45{ }^{\circ} \mathrm{C}$ for
$24 \mathrm{~h}$. All other chemicals were obtained from SCRC and used without further purification.

\subsection{Synthesis of amino-functionalized silica nanoparticles} $\left(\mathrm{SiO}_{2}-\mathrm{NH}_{2}\right)$

Functionalization of nanosilica by converting most of the surface silanol groups into amino groups was carried out as follows. The silica dispersion (2.00 $\mathrm{g} \mathrm{SiO}_{2}, 2 \mathrm{wt} \%$ in toluene) was transferred into a $250 \mathrm{~mL}$ 2-neck round-bottom flask and then put it on a magnetic stirrer fitted with a reflux condenser. APTES (4.38 mL, $18.72 \mathrm{mmol}$ ) was added, pumped and vacuum-purged with nitrogen gas three times. Then the reaction mixture was gently refluxed overnight under nitrogen. After cooling to room temperature, the nanoparticles were isolated by centrifugation at $4000 \mathrm{rpm}$ for $10 \mathrm{~min}$. After discarding the supernatant, the sediments were crushed and redispersed in toluene and centrifuged again. The centrifugation-redispersion cycle was repeated twice using dichloromethane and acetone, separately. The functionalized silica was dried in vacuum at $45{ }^{\circ} \mathrm{C}$ for $24 \mathrm{~h}$ and then stored in a silica gel desiccator. The amount of amino groups introduced onto the silica surface was determined by elemental analysis. The results of the elemental analysis of the same sample, which was tested twice under the same conditions, are shown in Table 1 . Since there is only one $\mathrm{N}$ atom in each APTES molecule, the graft density of amino $\left(D_{\mathrm{NH} 2}\right)$ is also the graft density of APTES, which can be calculated by eq (1):

$$
D_{\mathrm{NH}_{2}}=\frac{C_{\mathrm{N}}}{M_{\mathrm{N}}}
$$

wherein $C_{\mathrm{N}}$ is the $\mathrm{N}$ content according to the elemental analysis, and $M_{\mathrm{N}}$ is the molecular weight of the $\mathrm{N}$ atom. As a result, the graft density of APTES is calculated to be $1.64 \mathrm{mmol} \mathrm{g}^{-1}$.

\subsection{Synthesis of the silica macroinitiator $\left(\mathrm{SiO}_{2}-\mathrm{Br}\right)$}

To carry out the SI-ATRP of the ionic liquid, the initiator was first grafted onto the $\mathrm{SiO}_{2}$ particles. The toluene suspension of amino-functionalized silica nanoparticles $\left(1.5 \mathrm{~g} \mathrm{SiO}_{2}-\mathrm{NH}_{2}\right.$, $2 \mathrm{wt} \%$ in toluene) was mixed with triethylamine $(1.71 \mathrm{~mL}, 12.3$ $\mathrm{mmol})$ in a $150 \mathrm{~mL}$ flask. After cooling to $0{ }^{\circ} \mathrm{C}$, BiBB $(0.61 \mathrm{~mL}$, $4.92 \mathrm{mmol}$ ) was added dropwise. The solution was stirred at $0{ }^{\circ} \mathrm{C}$ for $2 \mathrm{~h}$ and then at room temperature for another $22 \mathrm{~h}$. The nanoparticles were purified and isolated following similar procedures for the synthesis of amino-functionalized silica nanoparticles described in Section 2.2. The final product was dried in a vacuum oven at $45{ }^{\circ} \mathrm{C}$ for $24 \mathrm{~h}$.

Table 1 Repeated elemental analysis of $\mathrm{SiO}_{2}$-APTES

\begin{tabular}{llllll}
\hline No. & $\begin{array}{l}\text { Weight } \\
(\mathrm{mg})\end{array}$ & $\begin{array}{l}\text { Content }[\mathrm{N}] \\
(\%)\end{array}$ & $\begin{array}{l}\text { Content }[\mathrm{C}] \\
(\%)\end{array}$ & $\begin{array}{l}\text { Content }[\mathrm{H}] \\
(\%)\end{array}$ & $\begin{array}{l}\mathrm{C} / \mathrm{N} \\
\text { ratio }\end{array}$ \\
\hline 1 & 5.160 & 2.296 & 6.301 & 1.991 & 2.744 \\
2 & 4.520 & 2.302 & 6.136 & 1.852 & 2.665
\end{tabular}




\subsection{Synthesis of the TMS-labeled ATRP initiator}

2-(Trimethylsilyl)ethanol (1.419 g, $12.0 \mathrm{mmol}$ ), anhydrous $\mathrm{CH}_{2} \mathrm{Cl}_{2}$ $(10 \mathrm{~mL})$, and triethylamine $(1.95 \mathrm{~mL}, 14.0 \mathrm{~mol})$ were added into a $60 \mathrm{~mL}$ round-bottom flask equipped with a rubber plug. After the flask was immersed into an ice-water bath, BiBB $(1.73 \mathrm{~mL}$, $14.0 \mathrm{mmol}$ ) in anhydrous $\mathrm{CH}_{2} \mathrm{Cl}_{2}(5 \mathrm{~mL})$ was added dropwise into the previous solution. The reaction was continued at $0{ }^{\circ} \mathrm{C}$ for another $2 \mathrm{~h}$ and then at room temperature for $24 \mathrm{~h}$. The reaction mixture was then filtered to remove the salt, and then washed successively with $1 \mathrm{~mol} \mathrm{~L}^{-1} \mathrm{HCl}$ solution, $1 \mathrm{~mol} \mathrm{~L}^{-1} \mathrm{NaHCO}_{3}$ solution, and deionized water. The organic phase was dried with anhydrous $\mathrm{MgSO}_{4}$ overnight. After filtration and removal of dichloromethane on a rotary evaporator, a faint yellow viscous liquid of 2-(trimethylsilyl)ethyl 2-bromo-2-methylpropanoate (TMS-EBMP) was obtained. ${ }^{1} \mathrm{H}$ NMR $\left(400 \mathrm{MHz}, \mathrm{CDCl}_{3}\right) \delta(\mathrm{ppm})$ : $4.30(\mathrm{t}, 2 \mathrm{H}), 1.94(\mathrm{~s}, 6 \mathrm{H}), 1.05(\mathrm{~s}, 2 \mathrm{H}), 0.08(\mathrm{t}, 9 \mathrm{H})$.

\subsection{Synthesis of the ionic liquid monomer [VBTMA] $\left.\mathrm{BF}_{4}\right]$}

The monomer was synthesized from ammonium halide using ion exchange reaction as follows: [VBTMA][Cl] $(2.54 \mathrm{~g}, 0.012$ $\mathrm{mol}), \mathrm{NaBF}_{4}(1.45 \mathrm{~g}, 0.0132 \mathrm{~mol})$ and acetonitrile $\left(\mathrm{CH}_{3} \mathrm{CN}\right)$ $(15 \mathrm{~mL})$ were added to a $60 \mathrm{~mL}$ round-bottom flask. The mixture was stirred overnight. The salt dissolved gradually and finally formed a white precipitate. The precipitate was removed by filtration. The filtrate was concentrated, and then poured into ether. The precipitated white crystal was collected and dried under vacuum at room temperature and stored in a refrigerator. In addition, silver nitrate testing indicated the absence of chloride. [VBTMA] $\left[\mathrm{BF}_{4}\right]$ : ${ }^{1} \mathrm{H}$ NMR $\left(400 \mathrm{MHz}, \mathrm{DMSO}-d_{6}\right) \delta(\mathrm{ppm})$ : $7.62(\mathrm{~d}, 2 \mathrm{H}), 7.51(\mathrm{~d}, 2 \mathrm{H}), 6.81(\mathrm{q}, 1 \mathrm{H}), 5.96(\mathrm{~d}, 1 \mathrm{H}), 5.38(\mathrm{~d}, 1 \mathrm{H})$, 4.50 (s, 2H), 3.02 (s, 9H); mp: $160-164{ }^{\circ} \mathrm{C}$.

\subsection{Synthesis of $\mathrm{SiO}_{2}-\mathrm{P}[\mathrm{VBTMA}]\left[\mathrm{BF}_{4}\right]$ nanoparticles}

The initiator-immobilized silica particles, the ionic liquid monomer [VBTMA] $\left[\mathrm{BF}_{4}\right]$ (2.634 g, $\left.10.0 \mathrm{mmol}\right)$, dimethylformamide (DMF) $(4.0 \mathrm{~mL})$, and $\mathrm{CuCl}(0.0099 \mathrm{~g}, 0.1 \mathrm{mmol})$ were added in sequence into a $25 \mathrm{~mL}$ dry 3-neck flask, and then sealed with a rubber septum rapidly. The flask was degassed by purging with nitrogen for $10 \mathrm{~min}$. TMS-labeled free initiator TMS-EBMP (13.36 $\mathrm{mg}, 0.05 \mathrm{mmol}$ ) was added to the mixture via a syringe, and the solution was stirred for about $10 \mathrm{~min}$ until it became homogeneous, followed by the addition of the ligand (PMDETA, $20.8 \mu \mathrm{L}, 0.1 \mathrm{mmol})$ via a syringe to start the surface-initiated polymerization. After a desired reaction time at $90{ }^{\circ} \mathrm{C}$, the $\mathrm{SiO}_{2}-\mathrm{P}[\mathrm{VBTMA}]\left[\mathrm{BF}_{4}\right]$ particles were isolated by centrifugation. To remove physically absorbed polymer chains, the $\mathrm{SiO}_{2}-\mathrm{P}-$ [VBTMA] $\left[\mathrm{BF}_{4}\right]$ particles were washed with DMF several times and then dried under vacuum at $70{ }^{\circ} \mathrm{C}$. The supernatant was concentrated, and then precipitated in a cold methanol-water $(4 / 1 \mathrm{v} / \mathrm{v})$ mixture. The polymer $\left(\mathrm{P}[\mathrm{VBTMA}]\left[\mathrm{BF}_{4}\right]\right)$ generated in the solution by the sacrificial initiator was obtained and dried under vacuum at $45{ }^{\circ} \mathrm{C}$. Then the samples were kept in a desiccator for ${ }^{1} \mathrm{H}$ NMR measurement. P[VBTMA] $\left[\mathrm{BF}_{4}\right]:{ }^{1} \mathrm{H}$ NMR $\left(400 \mathrm{MHz}, \mathrm{DMSO}-d_{6}\right) \delta(\mathrm{ppm}): 7.09$ (br, 2H), 6.46 (br, 2H), 4.30 (br, 2H), 2.88 (br, 9H), 1.50 (br, 3H). Elemental analysis: calculated for $\mathrm{C}_{12} \mathrm{H}_{18} \mathrm{NBF}_{4}$ : C, 54.75; H, 6.84; N, 5.32. Found: C, 50.78; H, 7.00; N, 5.05.

\subsection{Characterizations}

${ }^{1} \mathrm{H}$ nuclear magnetic resonance $\left({ }^{1} \mathrm{H}\right.$ NMR) spectra were recorded on a Bruker Advance II $400 \mathrm{MHz}$ NMR spectrometer operated at $400 \mathrm{MHz}$ in $5 \mathrm{~mm}$ tubes using $\mathrm{CDCl}_{3}$ or DMSO- $d_{6}$ as the solvent.

Fourier transform infrared spectra (FT-IR) of the bare-silica, $\mathrm{SiO}_{2}-\mathrm{Br}$ and $\mathrm{SiO}_{2}-\mathrm{P}[\mathrm{VBTMA}]\left[\mathrm{BF}_{4}\right]$ were recorded using $\mathrm{KBr}$ pellets in transmittance mode between 4000 and $400 \mathrm{~cm}^{-1}$ on a Nicolet Avatar 330 FT-IR spectrophotometer.

The melting point of the monomer $\left[\mathrm{VBTMA}^{\mathrm{B}}\right]\left[\mathrm{BF}_{4}\right]$ was measured by an X-4 digital display microscopic melting point meter corrected using acetanilide with a melting point of $114{ }^{\circ} \mathrm{C}$ as the standard substance.

Thermogravimetric analysis (TGA) was carried out on an SDTQ 600 instrument at a heating rate of $10{ }^{\circ} \mathrm{C} \mathrm{min}^{-1}$ from room temperature to $800{ }^{\circ} \mathrm{C}$ under a nitrogen atmosphere.

Elemental analysis was done using a Vario EL III elemental analyzer.

Scanning electron microscopy (SEM) observation was made using a Hitachi S-4800 microscope at an acceleration voltage of $10 \mathrm{kV}$. Each sample was prepared as follows: $0.2 \mathrm{mg} \mathrm{mL}^{-1}$ ethanol solution of bare-silica and $\mathrm{SiO}_{2}-\mathrm{Br}$, and $0.2 \mathrm{mg} \mathrm{mL}$ DMF solution of $\mathrm{P}[\mathrm{VBTMA}]\left[\mathrm{BF}_{4}\right]$ and $\mathrm{SiO}_{2}-\mathrm{P}[\mathrm{VBTMA}]\left[\mathrm{BF}_{4}\right]$ were mounted onto silicon wafers, dried at room temperature, pasted onto conducting resins, and then tested after spraying with platinum.

X-ray photoelectron spectroscopy (XPS) analysis was carried out on a PHI quantum 2000 scanning ESCA microprobe, using an $\mathrm{Al} \mathrm{K}_{\alpha 12}$ radiation as the exciting source with a binding energy of $1486.60 \mathrm{eV}$ and voltage of $15 \mathrm{kV}$ in a CAE pattern. The binding energy of carbon $(\mathrm{C} 1 \mathrm{~s}=284.8 \mathrm{eV})$ was used as the energy calibration standard.

Dynamic light scattering (DLS) tested on a Malvern light scattering instrument (Nano ZS, Particle Sizing Systems) was used to measure the particle size of the nanoparticles. All hydrodynamic diameters in the text are the averages of the intensity-weighted distributions at $20{ }^{\circ} \mathrm{C}$. The samples were prepared in DMF and filtered with a $0.45 \mu \mathrm{m}$ nylon syringe filter.

Electrochemical impedance spectroscopy was used to measure the ionic conductivity of the materials. The impedance spectra were recorded on a CHI660D electrochemical workstation at room temperature and in the temperature range of 303.15$353.15 \mathrm{~K}$. The samples were made into wafers beforehand, and sandwiched between a pair of stainless steel blocking electrodes and placed in a temperature controlled furnace to be maintained at various constant temperatures for at least $1 \mathrm{~h}$ prior to each measurement. The data were collected over a frequency range of $1-10^{6} \mathrm{~Hz}$ with an amplitude of $5 \mathrm{mV}$ for an open circuit potential at different temperatures. The thickness and the diameter of the samples were measured by a vernier caliper. The bulk resistance is obtained from the Nyquist plots. The conductivity is calculated according to the following equation:

$$
\sigma=\frac{L}{R S}
$$


where $L$ is the thickness of the composite wafer, $S$ is the area of the composite wafer and $R$ is the bulk resistance.

The X-ray diffraction (XRD) patterns were recorded on an X'pert PRO X-ray diffractometer operating in normal transmission mode using $\mathrm{Cu} \mathrm{K} \alpha$ radiation $(\lambda=1.5406 \AA)$.

\section{Results and discussion}

\subsection{Characterization of the $\mathrm{SiO}_{2}-\mathrm{P}[\mathrm{VBTMA}]\left[\mathrm{BF}_{4}\right]$ nanocomposites}

Core-shell $\mathrm{SiO}_{2}-\mathrm{P}[\mathrm{VBTMA}]\left[\mathrm{BF}_{4}\right]$ was prepared via SI-ATRP on the macroinitiator surface (see Scheme 1). The FT-IR spectra of the silica particles, $\mathrm{SiO}_{2}-\mathrm{Br}$, and $\mathrm{SiO}_{2}-\mathrm{P}[\mathrm{VBTMA}]\left[\mathrm{BF}_{4}\right]$ are shown in Fig. 1. For bare silica (Fig. 1(a)), the characteristic absorption peaks of the tetrahedral silica structures occur at $1110 \mathrm{~cm}^{-1}$ ( $\mathrm{Si}-\mathrm{O}$ stretching) and $474 \mathrm{~cm}^{-1}$ ( $\mathrm{Si}-\mathrm{O}$ bending). A $\mathrm{Si}-\mathrm{O}-\mathrm{Si}$ bending peak at $808 \mathrm{~cm}^{-1}$ is observed. In the spectrum of $\mathrm{SiO}_{2}-$ Br (Fig. 1(b)), a small peak at $1538 \mathrm{~cm}^{-1}$ (N-H bending) is observed, indicating the existence of the amide group. Peaks at $2930 \mathrm{~cm}^{-1}$ and $1383 \mathrm{~cm}^{-1}$, arising from the $\mathrm{C}-\mathrm{H}$ stretching and bending vibration of the initiator, can also be observed. In the spectrum of $\mathrm{SiO}_{2}-\mathrm{P}$ [VBTMA] $\left[\mathrm{BF}_{4}\right]$ (Fig. 1(c)), the characteristic peaks of both $\mathrm{SiO}_{2}$ and the polymer shell are included. The peaks at $857 \mathrm{~cm}^{-1}, 891 \mathrm{~cm}^{-1}$ and $920 \mathrm{~cm}^{-1}$, attributed to the $\mathrm{C}-\mathrm{H}$ bending vibration, along with the two sharp peaks at 1490 $\mathrm{cm}^{-1}$ and $1419 \mathrm{~cm}^{-1}$ are the characteristic peaks of the benzene ring in $\mathrm{P}[\mathrm{VBTMA}]\left[\mathrm{BF}_{4}\right]$, indicating that $\mathrm{P}[\mathrm{VBTMA}]\left[\mathrm{BF}_{4}\right]$ was successfully grafted onto the surface of the nanosilica particles. The ${ }^{1} \mathrm{H}$ NMR spectrum of [VBTMA] $\left[\mathrm{BF}_{4}\right]$ in Fig. 2(a) shows the appearance of two sharp doublets at $7.62 \mathrm{ppm}$ and $7.51 \mathrm{ppm}$, corresponding to protons on the benzene ring group. One



Scheme 1 Synthesis route of the "core-shell" nanocomposites.



Fig. 1 FT-IR spectra of (a) bare silica, (b) $\mathrm{SiO}_{2}-\mathrm{Br}$ and (c) $\mathrm{SiO}_{2}-\mathrm{P}$ [VBTMA] $\left[\mathrm{BF}_{4}\right]$.



Fig. $2{ }^{1} \mathrm{H}$ NMR spectra of (a) [VBTMA][BF 4 and (b) P[VBTMA] $\left[\mathrm{BF}_{4}\right]$.

quartet centered at $6.81 \mathrm{ppm}$, and two doublets at $5.96 \mathrm{ppm}$ and $5.38 \mathrm{ppm}$, corresponding to the protons attached to carbons of the $\mathrm{C}=\mathrm{C}$ double bond on the styrene group, can also be observed. One singlet at $4.50 \mathrm{ppm}$ corresponds to the protons on methylene which is connected to the benzene ring. Another singlet at $3.02 \mathrm{ppm}$ corresponds to the protons on the methyl group connected to the nitrogen atom, and the singlet at 2.50 ppm is attributed to the solvent DMSO- $d_{6}$. One broad peak at around $1.50 \mathrm{ppm}$ of P[VBTMA $]\left[\mathrm{BF}_{4}\right]$ shown in Fig. 2(b), along with the disappearance of the peaks of the protons on the vinyl group, shows that $\mathrm{P}[\mathrm{VBTMA}]\left[\mathrm{BF}_{4}\right]$ was successfully synthesized.

To further confirm the immobilization of the initiator and $\mathrm{P}$ [VBTMA] $\left[\mathrm{BF}_{4}\right]$ on the surface of silica, the surface of modified silica was characterized by XPS. The XPS survey spectrum and high resolution elemental scan of $\mathrm{C} 1 \mathrm{~s}$, N1s, and Br3d recorded from the macroinitiator $\mathrm{SiO}_{2}-\mathrm{Br}$ surface as shown in Fig. 3 confirm the structure. The C1s core-level spectrum of the macroinitiator surface includes three peak components having binding energy at about $284.3 \mathrm{eV}, 287.0 \mathrm{eV}$, and $287.8 \mathrm{eV}$, attributable to the $\mathrm{C}-\mathrm{H} / \mathrm{C}-\mathrm{C}, \mathrm{C}-\mathrm{Br} / \mathrm{C}-\mathrm{NCO}$, and $\mathrm{O}=\mathrm{C}-\mathrm{N}$ species, respectively. The N1s peak at the binding energy of about 402.1 $\mathrm{eV}$ is attributed to the $\mathrm{O}=\mathrm{C}-\mathrm{N}$ species. The presence of the $\mathrm{Br} 3 \mathrm{~d}$ 


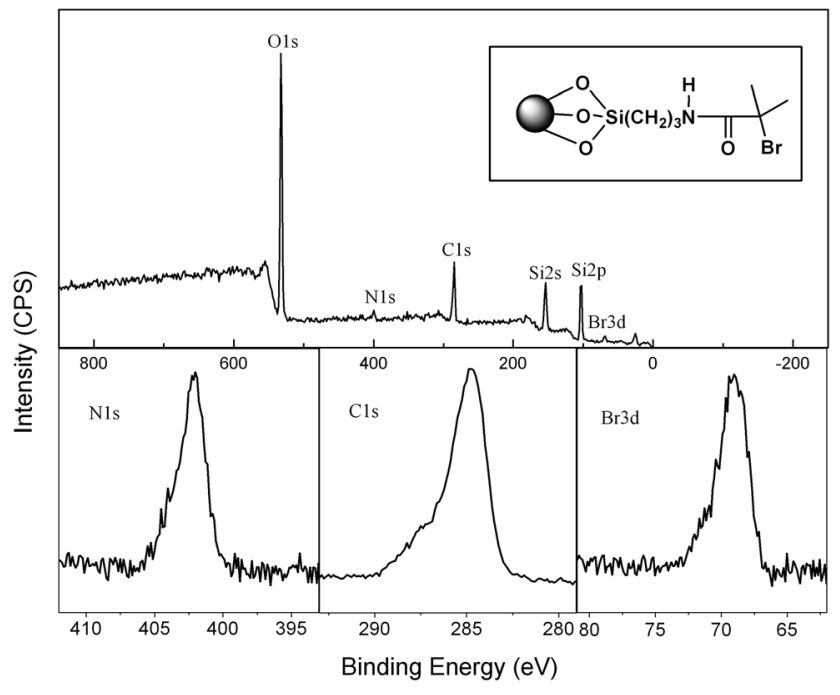

Fig. 3 The XPS survey spectrum and high-resolution elemental scan of $\mathrm{C} 1 \mathrm{~s}, \mathrm{~N} 1 \mathrm{~s}$, and $\mathrm{Br} 3 \mathrm{~d}$ of the macroinitiator $\mathrm{SiO}_{2}-\mathrm{Br}$ surface.

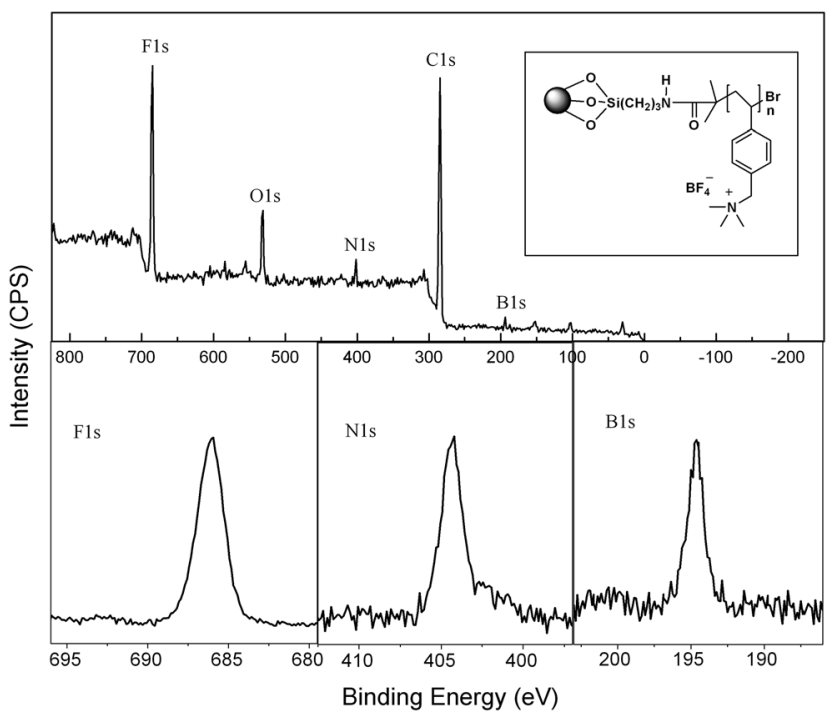

Fig. 4 The XPS survey spectrum and high-resolution elemental scan of $\mathrm{F} 1 \mathrm{~s}, \mathrm{~B} 1 \mathrm{~s}$, and $\mathrm{N} 1 \mathrm{~s}$ of the $\mathrm{SiO}_{2}-\mathrm{P}[\mathrm{VBTMA}]\left[\mathrm{BF}_{4}\right]$ surface.

peak at the binding energy of about $68.7 \mathrm{eV}$ and the appearance of the $\mathrm{O}=\mathrm{C}-\mathrm{N}$ peak component indicate that the initiator species for the subsequent SI-ATRP reaction has been successfully immobilized on the nanosilica surface via silanization and acylation reaction. Fig. 4 shows the typical XPS survey spectrum and high-resolution elemental scan of F1s, B1s, and N1s of the P [VBTMA] $\left[\mathrm{BF}_{4}\right]$ shell modified silica surface. The peaks for F1s (686.1 eV), B1s (194.6 eV), and N1s (404.2 eV) are clearly seen in the survey spectrum. The N1s peak at the binding energy of $404.2 \mathrm{eV}$ is mainly assigned to the positively charged nitrogen $\left(\mathrm{N}^{+}\right)$of the poly[(p-vinylbenzyl)trimethylammonium] cation. By calculating the peak area of each element, the $[\mathrm{N}]:[\mathrm{F}]:[\mathrm{B}]$ ratio for the P[VBTMA $]\left[\mathrm{BF}_{4}\right]$ shell modified silica surface was about $1.16: 3.62: 1$, which was in good agreement with the theoretical molar ratio of those atoms $(1: 4: 1)$.
In principle, the hydrodynamic diameter should increase upon complex formation as different amounts of [VBTMA] $\left.\mathrm{BF}_{4}\right]$ are grafted onto the nanosilica particles. Therefore, we try to employ DLS to obtain the hydrodynamic diameter of the hybrid nanoparticles in solution. The approximate linearity of the particle size $v s$. polymerization time is observed as shown in Fig. S1. $\dagger$

\subsection{Molecular weight measurement}

The characterization of well-defined poly-ionic materials remains a challenge for the presence of charged groups resulting in complicated and unreliable molecular weight (MW) characterization via gel permeation chromatography (GPC). He et al. demonstrated that the MW and molecular weight distribution (MWD) of poly(ionic liquid)s can be characterized by simply adding salts containing the same anions as the poly(ionic liquid)s into the GPC eluents. ${ }^{50}$ However, this leads to complicated post-processing of the data and it is not universal for all the poly(ionic liquid)s. Therefore, the molecular weight of the polymer that was grafted onto the nanosilica was measured with a TMS-labeled "sacrificial initiator" method by ${ }^{1} \mathrm{H}$ NMR. ${ }^{50-52}$ The ${ }^{1} \mathrm{H}$ NMR spectra of TMS-P[VBTMA][BF 4 at different polymerization times are shown in Fig. 5. The number average molecular weight of the precipitated TMS-P[VBTMA]$\left[\mathrm{BF}_{4}\right]$ obtained from ${ }^{1} \mathrm{H}$ NMR $\left(M_{\mathrm{n}, \mathrm{NMR}}\right)$ was calculated via eq (3):

$$
M_{\mathrm{n}, \mathrm{NMR}}=\frac{9 A_{\text {benzene }} M_{\text {monomer }}}{4 A_{\mathrm{TMS}}}+M_{\text {initiator }}
$$

where $A_{\text {benzene }}$ is the integrated area of the NMR peaks $(\sim 7.09$ and $6.46 \mathrm{ppm}$ ) of the $\mathrm{H}$ in the benzene rings, $A_{\mathrm{TMS}}$ is the integrated area of the NMR peak $(\sim 0.0 \mathrm{ppm})$ of the $\mathrm{H}$ in TMS groups, $M_{\text {monomer }}$ is the molecular weight of the [VBTMA] $\left[\mathrm{BF}_{4}\right]$ monomer, and $M_{\text {initiator }}$ is the molecular weight of the TMSlabeled initiator.

The calculated molecular weight increases with polymerization time as shown in Fig. 6. But it is regrettable that we could not get the MWD of P[VBTMA $]\left[\mathrm{BF}_{4}\right]$ through this method. Although there are a few reports showing that MALDI-TOF MS

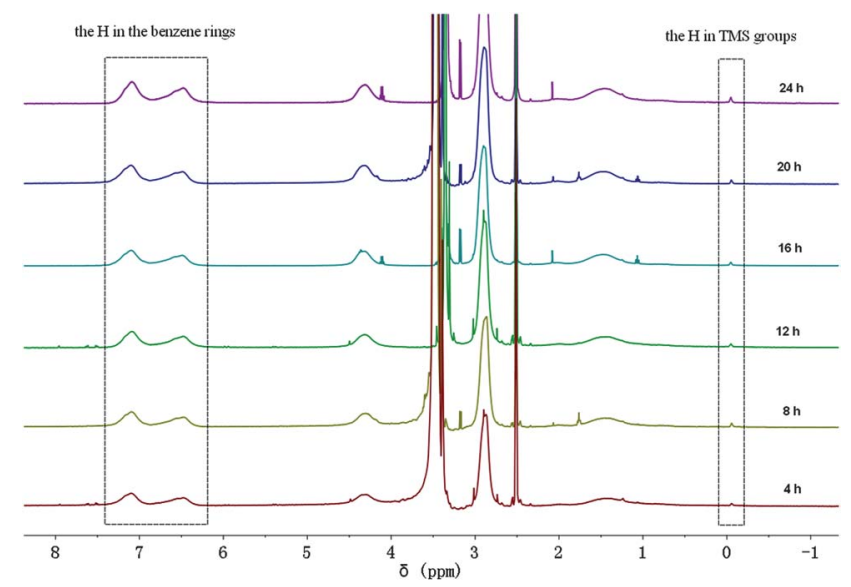

Fig. $5{ }^{1} \mathrm{H}$ NMR spectra of the TMS-P[VBTMA][BF 4 ] at different polymerization times. 


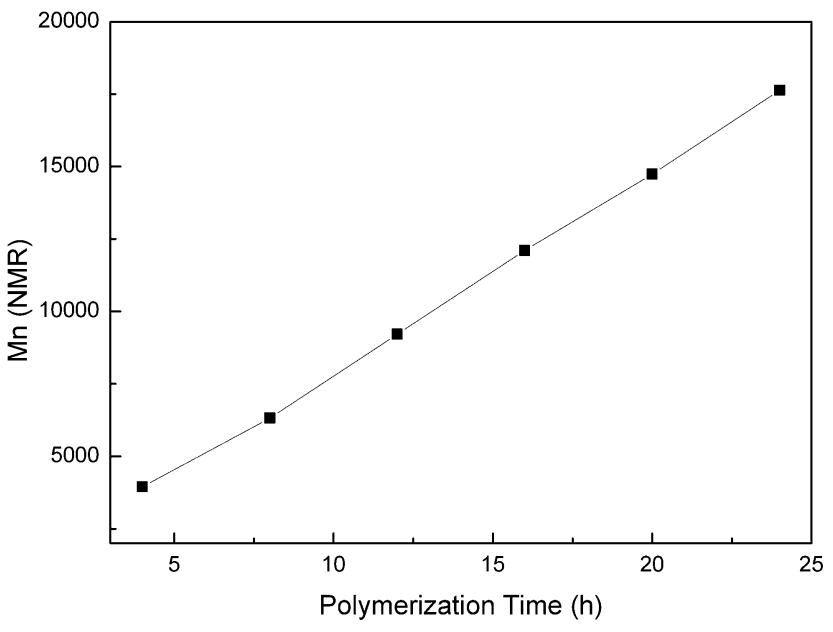

Fig. 6 Plot of $M_{n}$ of TMS-P[VBTMA] $\left[\mathrm{BF}_{4}\right]$ obtained from ${ }^{1} \mathrm{H}$ NMR.

worked for some charged polymers ${ }^{53,54}$ and quaternary ammonium salts can take advantage of their inherent matrix suppression effect (MSE) and analyte suppression effect (ASE), ${ }^{55}$ no peak was observed for $\mathrm{P}[\mathrm{VBTMA}]\left[\mathrm{BF}_{4}\right]$ by MALDI-TOF MS under many tested conditions with different matrices. Overall, the MW and MWD characterization of poly(ionic liquid)s is still a challenging issue that must be solved.

\subsection{Thermal properties}

Thermogravimetric curves of the silica particles, $\mathrm{SiO}_{2}-\mathrm{Br}$, and $\mathrm{SiO}_{2}-\mathrm{P}[\mathrm{VBTMA}]\left[\mathrm{BF}_{4}\right]$ (with a polymerization time of $16 \mathrm{~h}$ ) are shown in Fig. 7. Compared with the TGA diagram of the nanosilica particles, the much higher weight loss observed in the TGA diagram of $\mathrm{SiO}_{2}-\mathrm{Br}$ and $\mathrm{SiO}_{2}-\mathrm{P}[\mathrm{VBTMA}]\left[\mathrm{BF}_{4}\right]$ originates from the organic composition of the composites. Before thermal decomposition a slight weight loss of around $2.2 \%$, as shown in Fig. 7(b), is probably due to the evaporation of physically absorbed moisture, and this value is a little higher in the

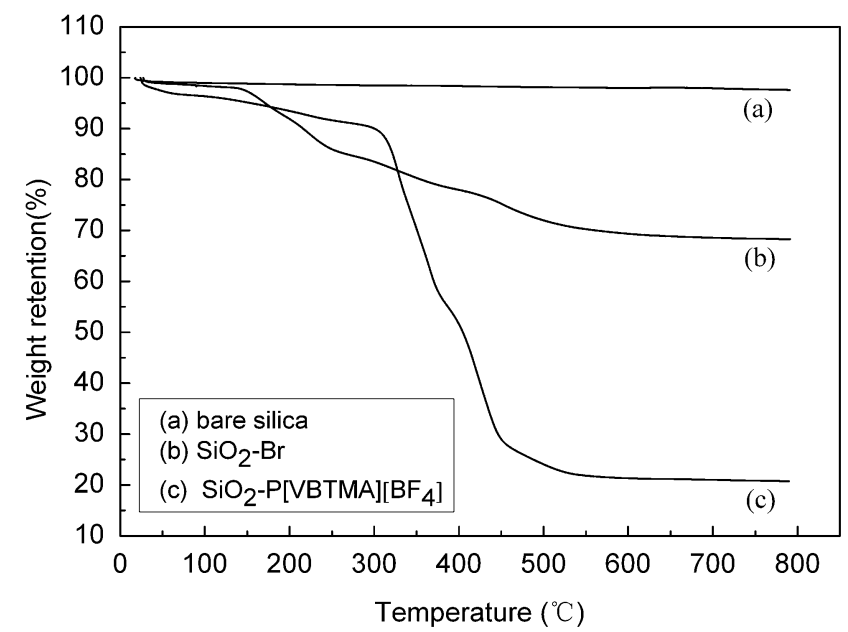

Fig. 7 TGA diagrams of (a) bare silica, (b) $\mathrm{SiO}_{2}-\mathrm{Br}$ and (c) $\mathrm{SiO}_{2}-\mathrm{P}$ [VBTMA] $\left[\mathrm{BF}_{4}\right]$.
$\mathrm{P}[\mathrm{VBTMA}]\left[\mathrm{BF}_{4}\right]$-grafted composite particles, which is caused by the high hydrophilicity of the $\mathrm{P}[\mathrm{VBTMA}]\left[\mathrm{BF}_{4}\right]$ shell. $\mathrm{SiO}_{2}-\mathrm{Br}$ clearly shows two types of distinct weight loss events: successive rapid decompositions at $140{ }^{\circ} \mathrm{C}$ and $260{ }^{\circ} \mathrm{C}$ due to the decomposition of the organic shell $v s$. the relatively slow weight loss region at around $520-700{ }^{\circ} \mathrm{C}$ due to the intermolecular condensation of the silica particles. The weight retention obtained for $\mathrm{SiO}_{2}-\mathrm{P}[\mathrm{VBTMA}]\left[\mathrm{BF}_{4}\right]$ (Fig. $7(\mathrm{c})$ ) at $750{ }^{\circ} \mathrm{C}$ is only $20.8 \%$. Using the weight retention at $750{ }^{\circ} \mathrm{C}$ obtained for $\mathrm{SiO}_{2}-$ $\mathrm{Br}(68.4 \%)$ as a reference, the $\mathrm{P}[\mathrm{MATMA}]\left[\mathrm{BF}_{4}\right]$ weight content is calculated to be $47.6 \%$. Two rapid thermal degradation events of $\mathrm{SiO}_{2}-\mathrm{P}[\mathrm{VBTMA}]\left[\mathrm{BF}_{4}\right]$ occur at $305{ }^{\circ} \mathrm{C}$ and $395{ }^{\circ} \mathrm{C}$ under a $\mathrm{N}_{2}$ atmosphere, which are due to the cleavage of the $\mathrm{P}[\mathrm{VBTMA}]\left[\mathrm{BF}_{4}\right]$ polymer backbone (or the so-called carbonation). The high decomposition temperature of $\mathrm{SiO}_{2}-\mathrm{P}[\mathrm{VBTMA}]\left[\mathrm{BF}_{4}\right]$ (over $300^{\circ} \mathrm{C}$ ) indicated its excellent thermal stability. Apparently, the present nanocomposite polyelectrolyte is fairly stable below $300{ }^{\circ} \mathrm{C}$, making it resistant to high temperature under continuous irradiation or other tough conditions.

\subsection{Morphology of the silica nanoparticles grafted with the $\mathrm{P}[\mathrm{VBTMA}]\left[\mathrm{BF}_{4}\right]$ shell}

The SEM images shown in Fig. 8 demonstrate the morphology and dispersion of bare silica, $\mathrm{SiO}_{2}-\mathrm{Br}, \mathrm{SiO}_{2}-\mathrm{P}[\mathrm{VBTMA}]\left[\mathrm{BF}_{4}\right]$, and $\mathrm{P}[\mathrm{VBTMA}]\left[\mathrm{BF}_{4}\right]$ with a polymerization time of $16 \mathrm{~h}$. The remarkable difference between the dispersion states of $\mathrm{SiO}_{2}$ particles, $\mathrm{SiO}_{2}-\mathrm{Br}$ particles and $\mathrm{SiO}_{2}-\mathrm{P}[\mathrm{VBTMA}]\left[\mathrm{BF}_{4}\right]$ particles (with a polymerization time of $16 \mathrm{~h}$ ) can be easily recognized. The slight increase in particle size can also be recognized. In Fig. 8(a), the high tendency to form aggregates is due to the high surface energy of the $\mathrm{SiO}_{2}$ particles. Compared with the dispersion of silica particles without surface treatment, $\mathrm{SiO}_{2}-\mathrm{Br}$ particles (Fig. 8(b)) show better dispersity with a little larger particle size. Due to the grafted polymer, the particles with the $\mathrm{P}[\mathrm{VBTMA}]\left[\mathrm{BF}_{4}\right]$ shell (Fig. 8(c)) show a slight increase in particle size. There is also a much less tendency to form larger aggregates than the $\mathrm{SiO}_{2}-\mathrm{Br}$ particles. This can be attributed to the high hydrophilicity of the $\mathrm{P}[\mathrm{VBTMA}]\left[\mathrm{BF}_{4}\right]$ shell and appears to

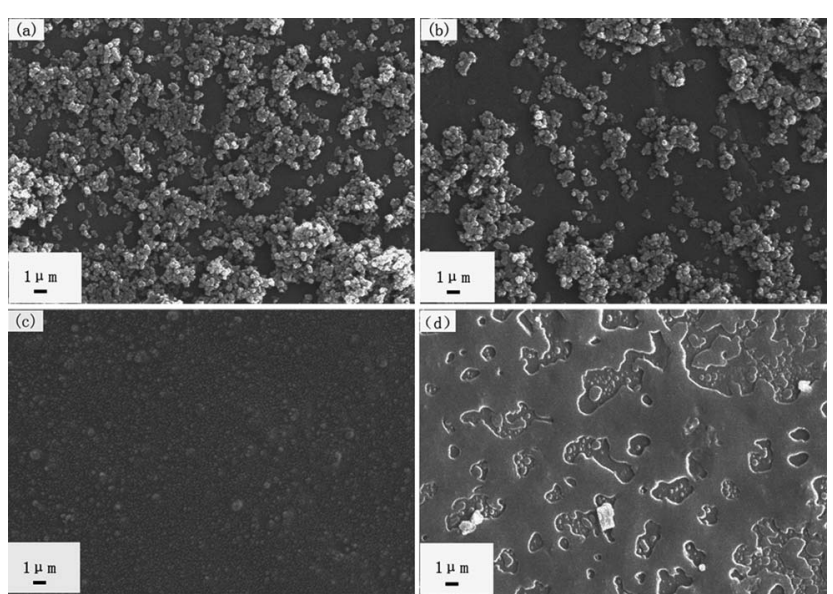

Fig. 8 SEM images of (a) bare silica, (b) $\mathrm{SiO}_{2}-\mathrm{Br}$, (c) $\mathrm{SiO}_{2}-\mathrm{P}[V B T M A]-$ $\left[\mathrm{BF}_{4}\right]$, and (d) P[VBTMA] $\left[\mathrm{BF}_{4}\right]$. 
depend strongly on the amorphous character of P[VBTMA]$\left[\mathrm{BF}_{4}\right] .^{56}$ As a result, highly dispersed membranes tend to be formed. As shown in Fig. 8(d), a laminated structure with a smooth surface is formed by pure poly(ionic liquid)s, while in Fig. 8(c), a membrane is formed by the nanocomposites. Many aggregations of nanoparticles are distributed on the membrane, offseting the blanks in the polymers.

On the other hand, the dispersion property of $\mathrm{SiO}_{2}-\mathrm{P}-$ [VBTMA $]\left[\mathrm{BF}_{4}\right]$ became better as the polymerization time prolonged (the SEM images are shown in Fig. S2†). A tentative inference on this result is that the percolation effect and aggregation effect of the nanoparticles decrease after the $\mathrm{P}[\mathrm{VBTMA}]\left[\mathrm{BF}_{4}\right]$ shell is grafted onto the nanosilica. The grafting of P[VBTMA $]\left[\mathrm{BF}_{4}\right]$ changes the dispersion of the nanoparticles. Therefore, the properties change.

\subsection{Ionic conductivity measurement}

Ionic conductivity of the pure polymer with a polymerization time of $16 \mathrm{~h}$ and that of the grafted nanocomposites with different polymerization times are listed in Table 2 . Since the cations of $\mathrm{P}[\mathrm{VBTMA}]\left[\mathrm{BF}_{4}\right]$ are immobilized on polymer chains, their migration is negligible and only the anions retain high mobility. Therefore, $\mathrm{P}[\mathrm{VBTMA}]\left[\mathrm{BF}_{4}\right]$ exhibits pure anionic conductivity.

The effect of the composition of nanoparticles on the ionic conductivity was also investigated. It has been demonstrated that the addition of inorganic nanoparticles such as $\mathrm{SiO}_{2}$ and $\mathrm{TiO}_{2}$ can increase the ionic conductivity of the low-fluidity solid electrolyte. ${ }^{22-26}$ As shown in Table 2, the ionic conductivity of $\mathrm{SiO}_{2}-\mathrm{P}[\mathrm{VBTMA}]\left[\mathrm{BF}_{4}\right]$ far exceeds that of the pure polymer $\mathrm{P}[\mathrm{VBTMA}]\left[\mathrm{BF}_{4}\right]$ with the same polymerization time (e.g. $\left.16 \mathrm{~h}\right)$. Furthermore, the hybrid nanomaterials of $\mathrm{SiO}_{2}-\mathrm{P}[\mathrm{VBTMA}]\left[\mathrm{BF}_{4}\right]$ with different contents of grafted $\mathrm{P}[\mathrm{VBTMA}]\left[\mathrm{BF}_{4}\right]$ have higher ionic conductivity than the pure polymer $\mathrm{P}[\mathrm{VBTMA}]\left[\mathrm{BF}_{4}\right]$ with a polymerization time of $16 \mathrm{~h}$. The ionic conductivity of nanocomposites increases to a maximum prior to decreasing as the polymerization time prolongs. For nanosilica, the ionic conductivity is only $0.40 \mu \mathrm{Sm}^{-1}$. At the beginning, though the graft density of $\mathrm{P}[\mathrm{VBTMA}]\left[\mathrm{BF}_{4}\right]$ on the surface is low, the ionic conductivity of the hybrid nanomaterial is not only much higher than that of pure nanosilica, but also a little higher than that of the pure polymer. It is because of the highly conductive layer formed at the polymer-silica interface. As the polymerization time is prolonged, $\mathrm{P}[\mathrm{VBTMA}]\left[\mathrm{BF}_{4}\right]$ grafted on the silica surface

Table 2 Ionic conductivity of pure nanosilica, P[VBTMA][BF $\left.F_{4}\right]$ and $\mathrm{SiO}_{2}-\mathrm{P}[\mathrm{VBTMA}]\left[\mathrm{BF}_{4}\right]$ with different polymerization times

\begin{tabular}{llll}
\hline No. & Sample name & $\begin{array}{l}\text { Polymerization } \\
\text { time }(\mathrm{h})\end{array}$ & $\begin{array}{l}\text { Conductivity } \\
\left(\mu \mathrm{S} \mathrm{cm}^{-1}\right)\end{array}$ \\
\hline 1 & $\mathrm{SiO}_{2}$ & 0 & 0.40 \\
2 & $\mathrm{SiO}_{2}-\mathrm{P}[\mathrm{VBTMA}]\left[\mathrm{BF}_{4}\right]-1$ & 4 & 32.8 \\
3 & $\mathrm{SiO}_{2}-\mathrm{P}[\mathrm{VBTMA}]\left[\mathrm{BF}_{4}\right]-2$ & 8 & 74.2 \\
4 & $\mathrm{SiO}_{2}-\mathrm{P}[\mathrm{VBTMA}]\left[\mathrm{BF}_{4}\right]-3$ & 12 & 68.6 \\
5 & $\mathrm{SiO}_{2}-\mathrm{P}[\mathrm{VBTMA}]\left[\mathrm{BF}_{4}\right]-4$ & 16 & 104 \\
6 & $\mathrm{SiO}_{2}-\mathrm{P}[\mathrm{VBTMA}]\left[\mathrm{BF}_{4}\right]-5$ & 20 & 26.8 \\
7 & $\mathrm{SiO}_{2}-\mathrm{P}[\mathrm{VBTMA}]\left[\mathrm{BF}_{4}\right]-6$ & 24 & 28.6 \\
8 & $\mathrm{P}[\mathrm{VBTMA}]\left[\mathrm{BF}_{4}\right]$ & 16 & 18.6
\end{tabular}

increases, the free ion number increases, and the ionic channel becomes wider, thus leading to a higher ionic conductivity. However, after a polymerization time of $16 \mathrm{~h}$, with a degree of polymerization (DP) of 45 and a MW of $12106 \mathrm{~g} \mathrm{~mol}^{-1}$ of the $\mathrm{P}[\mathrm{VBTMA}]\left[\mathrm{BF}_{4}\right]$ shell (according to ${ }^{1} \mathrm{H}$ NMR analysis shown in Fig. 6) and the $\mathrm{P}[\mathrm{VBTMA}]\left[\mathrm{BF}_{4}\right]$ content of $47.6 \%$ (according to TGA analysis), the ionic conductivity of the nanocomposites decreases with further increase of the grafted $\mathrm{P}[\mathrm{VBTMA}]\left[\mathrm{BF}_{4}\right]$. We attribute this phenomenon to the limited contact surface region of the silica core (Scheme 1). After a certain polymerization time, the fraction of the highly conductive layer decreases as the grafted P[VBTMA $]\left[\mathrm{BF}_{4}\right]$ shell increases, leading to the decreased ionic conductivity of the nanocomposites. This effect is likely due to a combination of the formation of the highly conductive layer and the increase in the number of charge carriers inside the conducting phase. A possible process of the change of ionic conductivity is proposed as follows according to their composition.

The structure of the nanocomposite polyelectrolyte is schematically presented in Scheme 2 . The nitrogen atoms in the polymer can interact with the hydroxyl groups on the nanoparticle surface, which can be supported by the IR analysis results (Fig. 1). Compared with Fig. 1(a), the band related to hydroxyl groups of silica in Fig. 1(c) shifts from 3435 to 3428 $\mathrm{cm}^{-1}$, which is caused by the hydrogen bonds formed between hydroxyl groups on silica particles and nitrogen atoms in the polymer. Thus, as shown in Scheme 2(a), a high ion density layer is formed around the silica particles. After a certain polymerization time, as the grafted $\mathrm{P}[\mathrm{VBTMA}]\left[\mathrm{BF}_{4}\right]$ chain becomes longer, the percolation effect and aggregation effect of the nanoparticles weaken, leading to wider channels for ion conduction (Scheme 2(b)). After a polymerization time of $16 \mathrm{~h}$, the content of nanosilica becomes too small (as shown in Scheme 2(c)) so that the increase in ionic conductivity of the nanocomposites is no longer evident, but the ionic conductivity is still higher than that of pure polymers. This also confirms that the addition of an adequate amount of inorganic nanoparticles can improve the ionic conductivity of the polymer electrolytes.

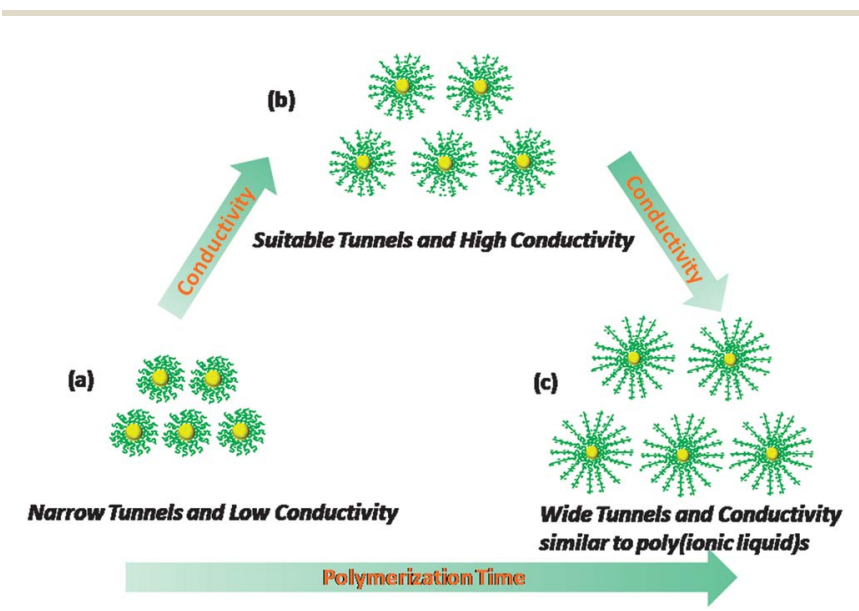

Scheme 2 Schematic of the arrangement structure of $\mathrm{SiO}_{2}-\mathrm{P}$ [VBTMA] $\left[\mathrm{BF}_{4}\right]$ at different compositions. 




Fig. 9 XRD patterns of poly(ionic liquid)s-based polyelectrolyte: (a) pure P[VBTMA][BF 4 ]; (b) $\mathrm{SiO}_{2}-\mathrm{P}[\mathrm{VBTMA}]\left[\mathrm{BF}_{4}\right]-1$; (c) $\mathrm{SiO}_{2}-\mathrm{P}[\mathrm{VBTMA}]-$ $\left[\mathrm{BF}_{4}\right]-2$; (d) $\mathrm{SiO}_{2}-\mathrm{P}[\mathrm{VBTMA}]\left[\mathrm{BF}_{4}\right]-3$; (e) $\mathrm{SiO}_{2}-\mathrm{P}[\mathrm{VBTMA}]\left[\mathrm{BF}_{4}\right]-4$; (f) $\mathrm{SiO}_{2}-\mathrm{P}[\mathrm{VBTMA}]\left[\mathrm{BF}_{4}\right]-5 ;(\mathrm{g}) \mathrm{SiO}_{2}-\mathrm{P}[\mathrm{VBTMA}]\left[\mathrm{BF}_{4}\right]-6$.

As is well-known, the crystallinity of polyelectrolytes has a significant effect on their ionic conductivity; ${ }^{22}$ therefore, X-ray diffraction measurement was performed to examine the crystallinity of pure $\mathrm{P}[\mathrm{VBTMA}]\left[\mathrm{BF}_{4}\right]$ with a polymerization time of 16 $\mathrm{h}$ and the $\mathrm{SiO}_{2}-\mathrm{P}[\mathrm{VBTMA}]\left[\mathrm{BF}_{4}\right]$ nanocomposites of different polymerization times. The XRD curves are shown in Fig. 9. Pure $\mathrm{P}[\mathrm{VBTMA}]\left[\mathrm{BF}_{4}\right]$ exhibits a broad peak at a $2 \theta$ angle of $12^{\circ}-27^{\circ}$. From curve (a) to curve (b), the large diffraction peak intensity of $\mathrm{XRD}$ for the $\mathrm{SiO}_{2}-\mathrm{P}[\mathrm{VBTMA}]\left[\mathrm{BF}_{4}\right]$ composites was slightly reduced after $\mathrm{P}[\mathrm{VBTMA}]\left[\mathrm{BF}_{4}\right]$ was grafted onto the nanosilica, which destroyed the crystalline part of $\mathrm{P}[\mathrm{VBTMA}]\left[\mathrm{BF}_{4}\right]$ and reduced the crystallinity of $\mathrm{P}[\mathrm{VBTMA}]\left[\mathrm{BF}_{4}\right]$. What is more, when the content of the nanosilica core decreased from curve (b) to curve (f), the relative intensity of the crystallization peaks further increased. The crystallinity of nanocomposites calculated from the XRD peaks for curve $(\mathrm{b}-\mathrm{g})$ is $0.49,0.56,0.73,0.83$, 0.87 , and 1.52 . This is attributed to the fact that some crystal defects and free volume appear at the interface of inorganic particles and the polymer after nanosilica is introduced into the conducting system. Hence, the crystallinity of P[VBTMA] $\left[\mathrm{BF}_{4}\right]$ increased and the proportion of the amorphous region decreased as the content of nanosilica decreased. There is significant motion of anions and even polymer chains in the amorphous phase and the free volume at the interface between $\mathrm{P}[\mathrm{VBTMA}]\left[\mathrm{BF}_{4}\right]$ and the silica core. The amorphous phase increases while the free volume decreases with the increase of the nanosilica content, thereby the change of ionic conductivity of $\mathrm{SiO}_{2}-\mathrm{P}[\mathrm{VBTMA}]\left[\mathrm{BF}_{4}\right]$ composites should be a cumulative result of the increasing amorphous phase region and the decreasing free volume. Through our experiments, we found that the optimal ionic conductivity was obtained from the nanocomposite with a polymerization time of $16 \mathrm{~h}$.

Based on the above discussion, the highest ionic conductivity value $\left(\sigma=104 \mu \mathrm{S} \mathrm{cm}^{-1}\right.$, in the order of $\left.10^{-4} \mathrm{~S} \mathrm{~cm}^{-1}\right)$ of the nanocomposites at room temperature is probably due to the formation of a highly conductive layer and high-efficiency ion migration tunnels at the polymer-silica interface. The hydrogen bond interactions make the grafted $\mathrm{P}[\mathrm{VBTMA}]\left[\mathrm{BF}_{4}\right]$ arrange around the $\mathrm{SiO}_{2}$ nanoparticles closely and densely, which is very important to form the highly conductive layer. As a result, highefficiency ion migration tunnels with mechanical stability are constructed, which is beneficial to the improvement of conductivity as mentioned above. As a whole, the interfacial resistance of this organic-inorganic nanocomposite polyelectrolyte influences the total resistance of the nanomaterial significantly and so does the crystallinity of the nanocomposite.

\subsection{Ion-conducting behavior}

It has been shown that at room temperature the optimal $\mathrm{SiO}_{2}-\mathrm{P}$ [VBTMA] $\left[\mathrm{BF}_{4}\right]$ nanocomposite electrolyte (with a polymerization time of $16 \mathrm{~h}$, DP of 45 and MW of $12106 \mathrm{~g} \mathrm{~mol}^{-1}$ of the $\mathrm{P}[\mathrm{VBTMA}]\left[\mathrm{BF}_{4}\right]$ shell, and the P[VBTMA $]\left[\mathrm{BF}_{4}\right]$ content of $47.6 \%$ ) has the highest ionic conductivity. The temperature dependence of ionic conductivity was also measured to further characterize the ionic conductivity properties of the electrolytes (Fig. 10). Both $\mathrm{P}[\mathrm{VBTMA}]\left[\mathrm{BF}_{4}\right]$ and $\mathrm{SiO}_{2}-\mathrm{P}[\mathrm{VBTMA}]\left[\mathrm{BF}_{4}\right]$ exhibit an exponential increase of ionic conductivity with temperature over a limited temperature range (303.15-353.15 $\mathrm{K}$ ), which is consistent with Arrhenius behavior. In fact, the data in Fig. 10 can be fitted well by the following Arrhenius equation (eq (4)):

$$
\sigma(T)=A \exp \left(\frac{-E_{\mathrm{a}}}{R T}\right)
$$

where $A$ is a constant, $E_{\mathrm{a}}$ is the activation energy, $R$ is the gas constant $\left(=8.314 \mathrm{~J} \mathrm{~mol}^{-1} \mathrm{~K}^{-1}\right)$, and $T$ is the absolute temperature.

The $E_{\mathrm{a}}$ of the pure P[VBTMA] $\left[\mathrm{BF}_{4}\right]$ electrolyte (Fig. 10(b)) is calculated to be $32.33 \mathrm{~kJ} \mathrm{~mol}^{-1}$. Such a high value indicates inferior ionic conduction. ${ }^{27,57}$ As for the nanocomposite with silica nanoparticles (Fig. 10(a)), the $E_{\mathrm{a}}$ is obviously reduced $\left(15.08 \mathrm{~kJ} \mathrm{~mol}^{-1}\right)$, because of the formation of high-efficiency ion exchange tunnels by introducing $\mathrm{SiO}_{2}$. This lower value is even

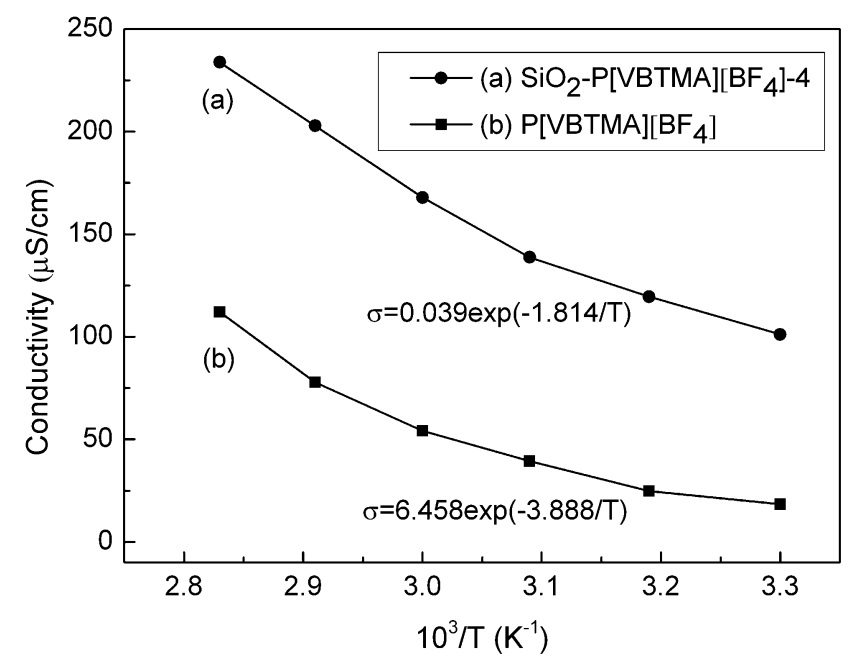

Fig. 10 Temperature dependence of ionic conductivity of (a) $\mathrm{SiO}_{2}-\mathrm{P}$ [VBTMA] $\left[\mathrm{BF}_{4}\right]-4$ and (b) P[VBTMA] $\left[\mathrm{BF}_{4}\right]$. 
comparable to the reported data of gel electrolytes for quasisolid-state dye-sensitized solar cells ${ }^{57}$ and thus may meet the requirement of their practical application in many fields.

\section{Conclusion}

In summary, a kind of novel core-shell $\mathrm{P}[\mathrm{VBTMA}]\left[\mathrm{BF}_{4}\right]$-based solid-state nanocomposite polyelectrolyte using rigid inorganic nanosilica as the core has been fabricated and was confirmed by FT-IR, ${ }^{1} \mathrm{H}$ NMR and XPS. The molecular weight of the polymer that was grafted onto the nanosilica was measured with a TMS-labeled "sacrificial initiator" method by ${ }^{1} \mathrm{H}$ NMR. TGA curves indicate good thermal stability of the nanocomposites. SEM images show their uniform and spherical morphology and dispersion information. By optimization of the composition (with a polymerization time of $16 \mathrm{~h}$ and the $\mathrm{P}[\mathrm{VBTMA}]\left[\mathrm{BF}_{4}\right]$ content of $\left.47.6 \%\right)$ of the electrolyte, considerable ionic conductivity above $10^{-4} \mathrm{~S} \mathrm{~cm}^{-1}$ is achieved at room temperature.

In addition, the enhancement of conductivity is related to the combination of the formation of a highly conductive layer and a decrease in crystallinity of $\mathrm{P}[\mathrm{VBTMA}]\left[\mathrm{BF}_{4}\right]$ according to the XRD result. Besides, the conductivity-temperature behaviors can be fitted well by the Arrhenius equation and it shows a lower activation energy $\left(15.08 \mathrm{~kJ} \mathrm{~mol}^{-1}\right)$ than pure P[VBTMA]$\left[\mathrm{BF}_{4}\right]$.

Overall, the tunable ionic conductivity was achieved by varying over the composition via changing the chain length of the grafted polymer and the size of the nanosilica particles. Also, due to the versatile applicability of SI-ATRP, the resulting ion-conducting nanocomposites are promising for applications that require moderate ion conduction.

\section{Acknowledgements}

The authors thank the National Natural Science Foundation of China (no. 21276213), the National Ministry of Science and Technology of China (no. 2012CB21500402) and the State-Key Laboratory of Chemical Engineering of Tsinghua University (no. SKL-ChE-13A05) for supporting this work. J. Luo acknowledges Research Fund KU Leuven for postdoctoral fellowship (PDM-short term). The authors also thank the anonymous referees for the helpful comments on this manuscript.

\section{References}

1 A. S. Shaplov, E. I. Lozinskaya, R. Losada, C. Wandrey, A. T. Zdvizhkov, A. A. Korlyukov, K. A. Lyssenko, I. A. Malyshkina and Y. S. Vygodskii, Polym. Adv. Technol., 2011, 22, 448-457.

2 B. Yameen, A. Kaltbeitzel, G. Glasser, A. Langner, F. Müller, U. Gösele, W. Knoll and O. Azzaroni, ACS Appl. Mater. Interfaces, 2010, 2, 279-287.

3 J. Y. Yuan and M. Antonietti, Polymer, 2011, 52, 1469-1482. 4 D. Mecerreyes, Prog. Polym. Sci., 2011, 36, 1629-1648.

5 B. Yu, F. Zhou, C. W. Wang and W. M. Liu, Eur. Polym. J., 2007, 43, 2699-2707.
6 K. Matsumoto and T. Endo, Macromolecules, 2009, 42, 45804584.

7 C. C. Yang, J. Membr. Sci., 2007, 288, 51-60.

8 A. Lewandowski and A. Świderska, Solid State Ionics, 2004, 169, 21-24.

9 S. Fotiadou, C. Karageorgaki, K. Chrissopoulou, K. Karatasos, I. Tanis, D. Tragoudaras, B. Frick and S. H. Anastasiadis, Macromolecules, 2013, 46, 2842-2855.

10 Y. Schneider, M. A. Modestino, B. L. McCulloch, M. L. Hoarfrost, R. W. Hess and R. A. Segalman, Macromolecules, 2013, 46, 1543-1548.

11 J. W. Zhang, X. B. Huang, H. Wei, J. W. Fu, Y. W. Huang and X. Z. Tang, J. Solid State Electrochem., 2012, 16, 101-107.

12 G. X. Wang, L. Sun, D. H. Bradhurst, S. Zhong, S. X. Dou and H. K. Liu, J. Power Sources, 2000, 88, 278-281.

13 Y. Liu, J. Y. Lee and L. Hong, J. Appl. Polym. Sci., 2003, 89, 2815-2822.

14 R. C. B. Scaravelli, R. L. Dazzi, F. C. Giacomelli, G. Machado, C. Giacomelli and V. Schmidt, J. Colloid Interface Sci., 2013, 397, 114-121.

15 Z. B. Li, T. Y. Chen, J. J. Nie, J. T. Xu, Z. Q. Fan and B. Y. Du, Mater. Chem. Phys., 2013, 138, 650-657.

16 S. Coe-Sullivan, W.-K. Woo, J. S. Steckel, M. Bawendi and V. Bulović, Org. Electron., 2003, 4, 123-130.

17 L. Lukyanova, L. Séon, A. Aradian, O. Mondain-Monval, J. Leng and R. Wunenburger, J. Appl. Polym. Sci., 2013, 128, 3512-3521.

18 C. Sanchez, B. Julián, P. Belleville and M. Popall, J. Mater. Chem., 2005, 15, 3559-3592.

19 J. T. Yang, Y. Sang, F. Chen, Z. D. Fei and M. Q. Zhong, J. Supercrit. Fluids, 2012, 62, 197-203.

20 H. J. Yu and Z. H. Luo, J. Polym. Sci., Part A: Polym. Chem., 2010, 48, 5570-5580.

21 F. Hoffmann, M. Cornelius, J. Morell and M. Fröba, Angew. Chem., Int. Ed., 2006, 45, 3216-3251.

22 D. R. MacFarlane, P. J. Newman, K. M. Nairn and M. Forsyth, Electrochim. Acta, 1998, 43, 1333-1337.

23 J.-W. Kim, K.-S. Ji, J.-P. Lee and J.-W. Park, J. Power Sources, 2003, 119-121, 415-421.

24 A. Walcarius, C. Delacote and S. Sayen, Electrochim. Acta, 2004, 49, 3775-3783.

25 D. Fu, B. Luan, S. Argue, M. N. Bureau and I. J. Davidson, J. Power Sources, 2012, 206, 325-333.

26 H. X. Wang, H. Li, B. F. Xue, Z. X. Wang, Q. B. Meng and L. Q. Chen, J. Am. Chem. Soc., 2005, 127, 6394-6401.

27 J. F. Shi, L. Wang, Y. L. Liang, S. J. Peng, F. Y. Cheng and J. Chen, J. Phys. Chem. C, 2010, 114, 6814-6821.

28 X. Y. He, W. Yang and X. W. Pei, Macromolecules, 2008, 41, 4615-4621.

29 W. P. Wang, H. M. Cao, G. J. Zhu and P. Wang, J. Polym. Sci., Part A: Polym. Chem., 2010, 48, 1782-1790.

30 T. Werne and T. E. Patten, J. Am. Chem. Soc., 2001, 123, 74977505.

31 H. D. Tang, J. B. Tang, S. J. Ding, M. Radosz and Y. Q. Shen, J. Polym. Sci., Part A: Polym. Chem., 2005, 43, 1432-1443.

32 A. Carlmark and E. Malmström, J. Am. Chem. Soc., 2002, 124, 900-901. 
33 W. H. Yu, E. T. Kang, S. P. Zhu and K. G. Neoh, J. Phys. Chem. $B, 2003,107,10198-10205$.

34 W. Feng, S. P. Zhu, K. Ishihara and J. L. Brash, Langmuir, 2005, 21, 5980-5987.

35 K. Ohno, T. Morinaga, K. Koh, Y. Tsujii and T. Fukuda, Macromolecules, 2005, 38, 2137-2142.

36 R. E. Behling, B. A. Williams, B. L. Staade, L. M. Wolf and E. W. Cochran, Macromolecules, 2009, 42, 1867-1872.

37 A. A. Brown, N. S. Khan, L. Steinbock and W. T. S. Huck, Eur. Polym. J., 2005, 41, 1757-1765.

38 S. Edmondson, C.-D. Vo and S. P. Armes, Macromolecules, 2007, 40, 5271-5278.

39 S. Edmondson, C.-D. Vo and S. P. Armes, Langmuir, 2008, 24, 7208-7215.

40 S. Edmondson, N. T. Nguyen, A. L. Lewis and S. P. Armes, Langmuir, 2010, 26, 7216-7226.

41 Y. Q. Shen, S. P. Zhu and R. Pelton, Macromolecules, 2001, 34, 5812-5818.

42 J. F. Moll, P. Akcora, A. Rungta, S. S. Gong, R. H. Colby, B. C. Benicewicz and S. K. Kumar, Macromolecules, 2011, 44, 7473-7477.

43 D. Dukes, Y. Li, S. Lewis, B. Benicewicz, L. Schadler and S. K. Kumar, Macromolecules, 2010, 43, 1564-1570.

44 D. Maillard, S. K. Kumar, B. Fragneaud, J. W. Kysar, A. Rungta, B. C. Benicewicz, H. Deng, L. C. Brinson and J. F. Douglas, Nano Lett., 2012, 12, 3909-3914.
45 A. Rungta, B. Natarajan, T. Neely, D. Dukes, L. S. Schadler and B. C. Benicewicz, Macromolecules, 2012, 45, 9303-9311.

46 T. Werne and T. E. Patten, J. Am. Chem. Soc., 1999, 121, 74097410.

47 A. Carlmark and E. E. Malmström, Biomacromolecules, 2003, 4, 1740-1745.

48 G. Morandi, L. Heath and W. Thielemans, Langmuir, 2009, 25, 8280-8286.

49 K. Ohno, K.-M. Koh, Y. Tsujii and T. Fukuda, Macromolecules, 2002, 35, 8989-8993.

50 H. K. He, M. J. Zhong, B. Adzima, D. Luebke, H. Nulwala and K. Matyjaszewski, J. Am. Chem. Soc., 2013, 135, 4227-4230.

51 M. Päch, D. Zehm, M. Lange, I. Dambowsky, J. Weiss and A. Laschewsky, J. Am. Chem. Soc., 2010, 132, 8757-8765.

52 Y. N. Zhou and Z. H. Luo, Polym. Chem., 2013, 4, 76-84.

53 B. Dervaux, F. Meyer, J.-M. Raquez, A. Olivier, F. E. D. Prez and P. Dubois, Macromol. Chem. Phys., 2012, 213, 1259-1265.

54 T. Biedroń and P. Kubisa, J. Polym. Sci., Part A: Polym. Chem., 2008, 46, 6961-6968.

55 X. W. Lou, J. L. J. Dongen, J. A. J. M. Vekemans and E. W. Meijer, Rapid Commun. Mass Spectrom., 2009, 23, 3077-3082.

56 J. B. Tang, H. D. Tang, W. L. Sun, M. Radosz and Y. Q. Shen, Polymer, 2005, 46, 12460-12467.

57 J. F. Shi, S. J. Peng, J. Pei, Y. L. Liang, F. Y. Cheng and J. Chen, ACS Appl. Mater. Interfaces, 2009, 1, 944-950. 